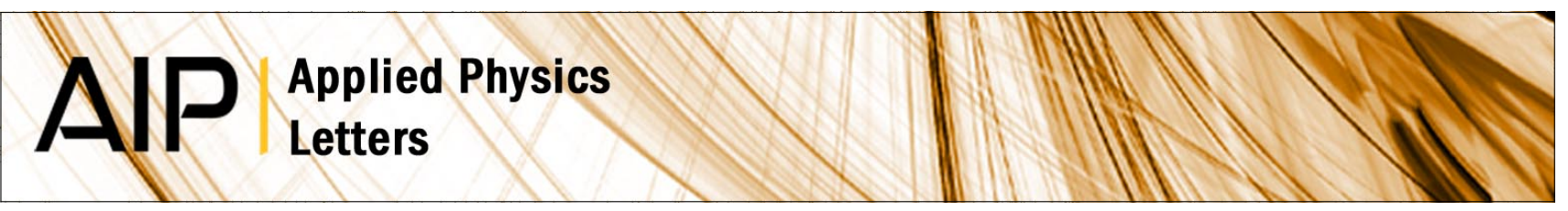

\title{
CdS photoluminescence inhibition by a photonic structure
}

A. Blanco, C. López, R. Mayoral, H. Míguez, F. Meseguer et al.

Citation: Appl. Phys. Lett. 73, 1781 (1998); doi: 10.1063/1.122280

View online: http://dx.doi.org/10.1063/1.122280

View Table of Contents: http://apl.aip.org/resource/1/APPLAB/v73/i13

Published by the American Institute of Physics.

\section{Related Articles}

Substrate effect on the room-temperature ferromagnetism in un-doped $\mathrm{ZnO}$ films Appl. Phys. Lett. 101, 031913 (2012)

Surface-bound-exciton emission associated with domain interfaces in $\mathrm{m}$-plane $\mathrm{ZnO}$ films Appl. Phys. Lett. 101, 011901 (2012)

Superradiance from one-dimensionally aligned $\mathrm{ZnO}$ nanorod multiple-quantum-well structures Appl. Phys. Lett. 100, 233118 (2012)

Optical properties of edge dislocations on (100) prismatic planes in wurtzite $\mathrm{ZnO}$ introduced at elevated temperatures

J. Appl. Phys. 111, 113514 (2012)

Emission from a dipole-forbidden energy state in a $\mathrm{ZnO}$ quantum dot induced by a near-field interaction with a fiber probe

Appl. Phys. Lett. 100, 223110 (2012)

\section{Additional information on Appl. Phys. Lett.}

Journal Homepage: http://apl.aip.org/

Journal Information: http://apl.aip.org/about/about_the_journal

Top downloads: http://apl.aip.org/features/most_downloaded

Information for Authors: http://apl.aip.org/authors

\section{ADVERTISEMENT}

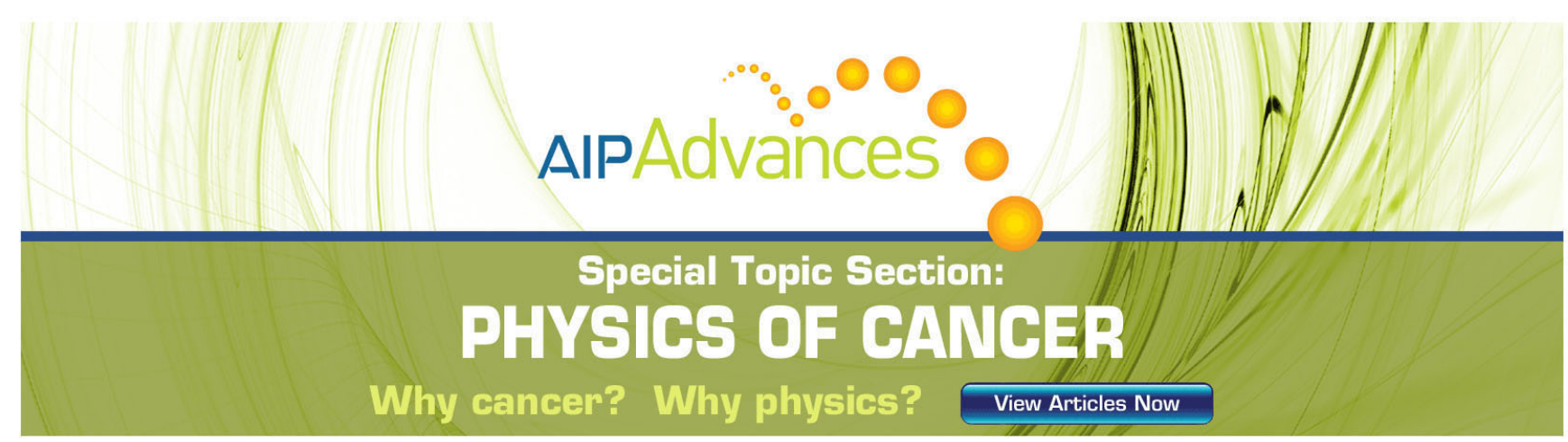




\section{CdS photoluminescence inhibition by a photonic structure}

A. Blanco, C. López, a) R. Mayoral, H. Míguez, and F. Meseguer

Instituto de Ciencia de Materiales de Madrid (CSIC), Cantoblanco 28049 Madrid, Spain and Departamento Física Aplicada, Unidad Asociada CSIC-UPV, 46022 Valencia, Spain

A. Mifsud

Instituto de Tecnología Química (CSIC-UPV), 46022 Valencia, Spain

J. Herrero

Departamento de Energías Renovables (CIEMAT), E-28040 Madrid, Spain

(Received 24 April 1998; accepted for publication 27 July 1998)

Here we present experimental evidence of the strong modification of the CdS photoluminescence when it is embedded in a $\mathrm{SiO}_{2}$ colloidal photonic crystal. When the emitted light matches a forbidden photonic band in the matrix, inhibition of the semiconductor photoluminescence is achieved. In this work we prove the effective control of this effect by means of the photonic lattice parameter of the host. CdS was grown by chemical bath deposition and its quality has been checked employing Raman spectroscopy and x-ray diffraction. Scanning electron microscopy is used to study the morphology of the composite. (C) 1998 American Institute of Physics.

[S0003-6951(98)01939-1]

In the last few years, since Yablonovich ${ }^{1}$ suggested the idea of photonic bands in periodic dielectric structures, interest in these types of materials has grown exponentially in both theoretical and experimental fields. Their important applications in the optoelectronic field have turned them into very appreciated materials. Synthetic opals made by means of sedimentation and ordering of $\mathrm{SiO}_{2}$ nanospheres have been shown to be excellent candidates to build up threedimensional (3D) photonic crystals in the near-infraredvisible range. ${ }^{2}$ Such materials have been proven to form a fcc (Ref. 3) lattice, and for such ordering a complete photonic band gap has been predicted. ${ }^{4}$ By filling the voids with another material or adjusting the $\mathrm{SiO}_{2}$ /air volume fraction, ${ }^{5}$ one can improve its photonic crystal properties.

Inhibition of spontaneous emission is a must in building lasers with a low threshold and this can be reached by means of photonic crystals, taking advantage of their particular photonic properties. Therefore, the synthesis of active materials (semiconductors, ${ }^{6,7}$ dye molecules, ${ }^{8-10}$ etc.) inside 3D photonic crystals operating in the visible range of the spectrum and matching efficiently their photoluminescence bands, is required. Recent work has shown the possibility of filling opaline structures with $\mathrm{CdS}$ by basically two growth methods: chemical bath deposition $(\mathrm{CBD})^{11}$ and vapor flow reactions, ${ }^{12,13}$ observing size effects and optical gain.

In this work we report on optical and photoluminescent properties of fcc packed submicron $\mathrm{SiO}_{2}$ spheres impregnated with CdS. The most important goal in this study is to show the influence a photonic structure has on CdS photoluminescence. The fabrication and characterization of the synthetic opals can be found elsewhere. ${ }^{2,3,14,15}$

$\mathrm{CdS}$ was grown by means of a (CBD) method in which the opaline sample is immersed in different solutions. ${ }^{16} \mathrm{Ba}-$ sically, the process consists of two stages which are repeated

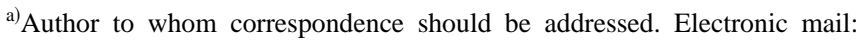
cefe@icmm.csic.es
}

several times. During the first stage, the opal is immersed in a $2.5 \times 10^{-2} \mathrm{M} \mathrm{CdSO}_{4}$ aqueous solution for several minutes. After that, the opal/ $\mathrm{CdSO}_{4}$ is placed in a $3.5 \times 10^{-2} \mathrm{M}$ $\mathrm{S}=\mathrm{C}\left(\mathrm{NH}_{2}\right)_{2}$ aqueous solution for the same amount of time. The time for each stage depends on particular experimental requirements. Both stages take place at $60{ }^{\circ} \mathrm{C}$ and are catalyzed by ammonia. Employing these growth conditions, the amount of CdS inside the opal is controlled and the growth on the external sample surface, which eventually could block the growth inside the opaline structure, is prevented.

X-ray diffraction (XRD), Raman scattering, and scanning electron microscopy (SEM) have been performed to characterize the infilled semiconductor. The XRD and Raman spectra can be seen in Fig. 1. In situ X-ray diffraction performed employing a Philips X'Pert diffractometer reveals the metastable cubic phase for $\mathrm{CdS}$, which remains stable after heating up to $700{ }^{\circ} \mathrm{C}$. In addition, both the first and
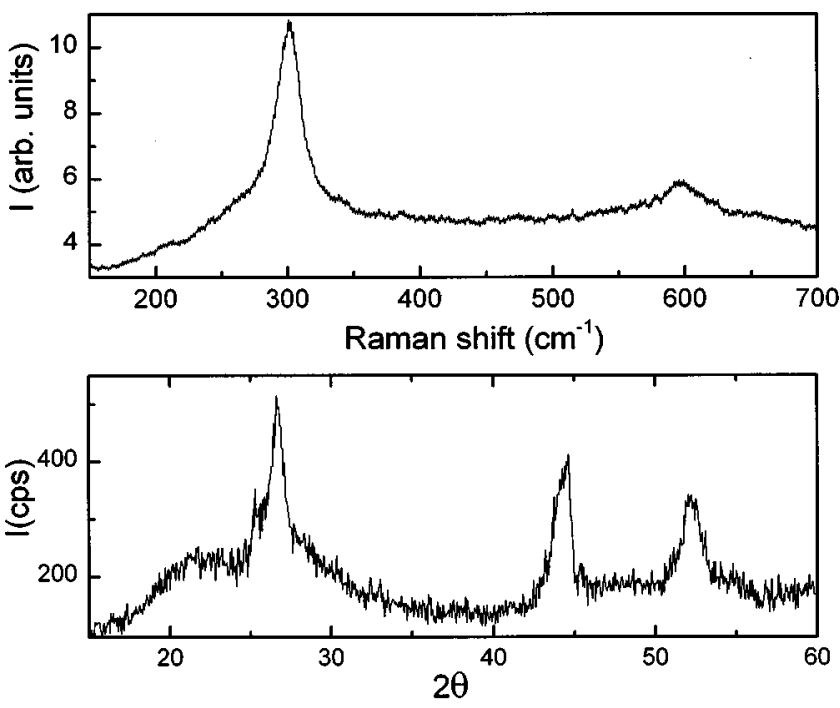

FIG. 1. XRD and Raman spectra of CdS infilled opal. 


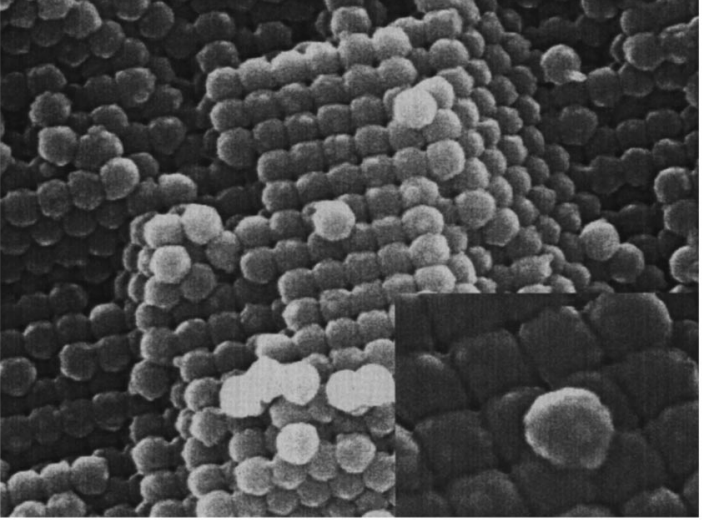

FIG. 2. SEM image of an internal face of $390 \mathrm{~nm}$ spheres opal infilled with CdS. The inset shows detail in the structure.

second harmonics of the LO CdS phonon can be observed by Raman spectroscopy. An asymmetric broadening of the Raman peak caused by the small crystal size can be observed as well. Both techniques indicate that the semiconductor crystalline quality is fairly good in comparison with similar work reported. $^{11-13}$

Figure 2 shows a SEM image of an internal (100) face of a sample infilled with $\mathrm{CdS}$. It can be seen that $\mathrm{CdS}$ crystals are uniformly distributed inside the sample. There is not, at least by this method of growth, privileged zones in which $\mathrm{CdS}$ grows more efficiently. The pore volume is reduced due to the $\mathrm{CdS}$ formation inside it, as can be readily seen in the inset of Fig. 2.

Optical transmission spectra at normal incidence of the empty and CdS infilled opals of $390 \mathrm{~nm}$ of sphere diameter can be observed in Fig. 3. The dip in transmission due to (111) Bragg diffraction planes of about $846 \mathrm{~nm}$ shifts to 890 $\mathrm{nm}$ in the $\mathrm{CdS}$ filled sample.

We can estimate the content of $\mathrm{CdS}$ by averaging its dielectric constant $(\epsilon \approx 6.25)$ with the air dielectric constant in the pore, considering $74 \%$ opal and $26 \%$ air/CdS and fitting the dip position through Bragg's law. ${ }^{17}$

This shift $(\Delta \lambda=44 \mathrm{~nm})$ corresponds to about $23 \%$ of the pore volume or $6 \%$ of the opal filled with $\mathrm{CdS}$. This value is an average of the $\mathrm{CdS}$ content inside the pore for the opal structure because in optical transmission measurement

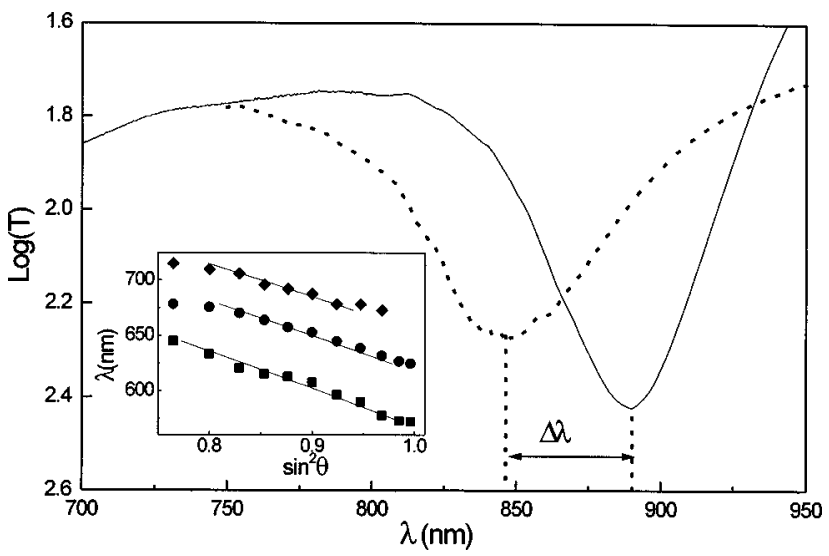

FIG. 3. Transmission spectra at normal incidence of both empty and CdS infilled opals of $390 \mathrm{~nm}$ of the sphere diameter. The inset shows the peak positions for bare (squares) and for opal with two different CBD treatments versus incidence angle along with the Bragg fit.

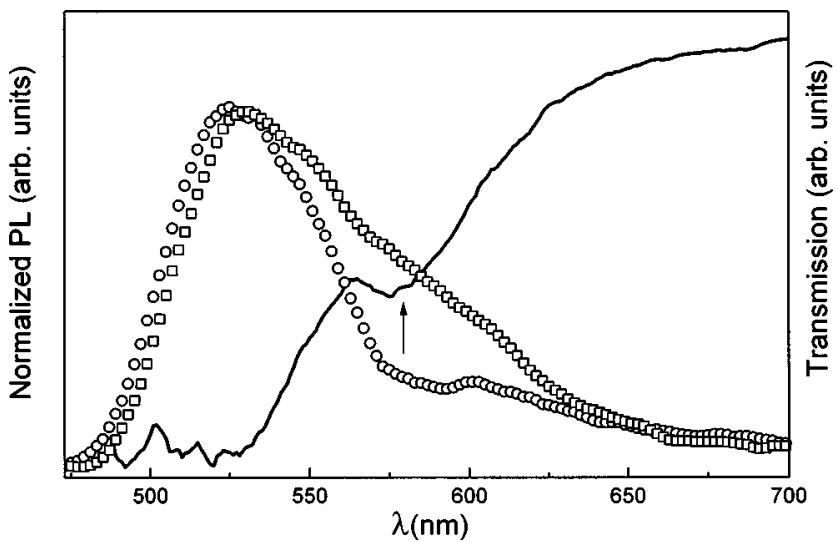

FIG. 4. PL and transmission (solid) spectra of a CdS infilled opal made up of $260 \mathrm{~nm}$ spheres. Circles are ordered samples and squares are ground samples. The arrows point the dip in transmission due to (111) planes.

all the opal structure is probed. According to SEM, the CdS content can be considered rather uniform.

The inset of the Fig. 3 shows the position of Bragg peaks versus the incidence angle for three different samples: bare (squares), 10\% (circles), and 23\% (diamonds) CdS infilled opals grown in two different increasing time stages starting from the same opal. As the CdS content increases the peak position shifts to higher wavelengths due to the change in the filling factor. Measuring at varying angles lets us reliably fit the $\mathrm{CdS}$ content.

Photoluminescence (PL) measurements were taken at room temperature under $457.9 \mathrm{~nm}$ Ar laser line excitation. The excitation and collection was performed in the (111) face of the opaline structure. It is worth remarking that no luminescence has been measured from our bare opals and any luminescence observed arises from the infilled semiconductor. Choosing the right sphere diameter to match the wavelength range where the CdS PL is emitted, host effects can be observed. For a sample with $260 \mathrm{~nm}$ spheres, the dip position for normal incidence appears at about $580 \mathrm{~nm}$. Figure 4 shows CdS PL spectra for an infilled opal [collected at a direction normal to the (111) planes] and that of the same semiconductor grown in the same matrix but after removing the photonic structure by grinding the opal/CdS system.

Although the PL spectra of CBD-grown CdS generally depend on the growth characteristics, the band centered in $530 \mathrm{~nm}(2.33 \mathrm{eV})$ has been associated with defect levels of interstitial sulphur. ${ }^{18}$ We have not found other PL bands which have been sometimes reported, generally placed at lower energies, which should indicate another type of defect such as cadmium or sulphur vacancies, interstitial cadmium, etc., confirming the semiconductor quality. ${ }^{16}$ The transmission (dotted line) shows the dip due to the (111) planes in addition to the semiconductor band edge. The measurement in transmission has been performed only at normal incidence since the peak position for higher angles falls into the semiconductor absorption range and no additional information can be extracted from it.

The dip in the PL spectrum coinciding with the dip in transmission for the $\mathrm{CdS}$ infilled ordered structure reveals a high coupling between the light emitted from the $\mathrm{CdS}$ and the low density of photonic states, for this range of wavelengths and this direction, imposed by the host matrix. When 


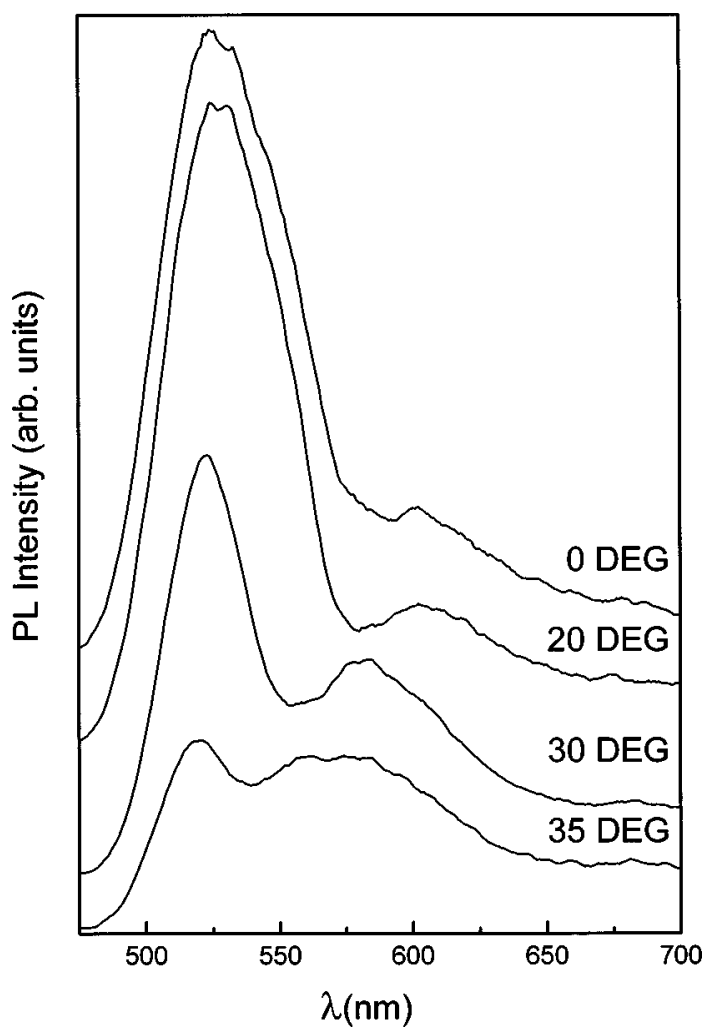

FIG. 5. PL spectra at different collection angles for the $260 \mathrm{~nm}$ sample. The curves have been vertically shifted for clarity.

the sample is ground and the order disappears in the system, the PL shape recovers the original $\mathrm{CdS}$ behavior and any photonic effect is lost. When the angle of PL collection is varied the dip in the photoluminescence band moves to lower wavelengths crossing all the band range and disappearing for angles greater than $35^{\circ}$. In Fig. 5 the PL spectra are shown for a few angles of collection: $0^{\circ}, 20^{\circ}, 30^{\circ}$, and $35^{\circ}$.

In this way, one can control the inhibition of PL in $\mathrm{CdS}$ by the sphere diameter. With a full photonic band gap or with a broad enough pseudogap effect that overlaps the whole PL band, the total inhibition of CdS luminescence should be possible, opening prospects for thresholdless laser action. According to this idea, a higher dielectric constant contrast-at least 4-in the photonic system is required. With $100 \%$ of the pore volume filled with $\mathrm{CdS}$ one can reach a dielectric constant contrast of 2.96. Although this value is lower than required, in those conditions the scattering strength $^{4}$ of the system will be increased by a factor of 2 , and so will its photonic properties, improving the efficiency of the inhibition effect.
On the other hand, this local effect can open the possibility of a narrow selection in the inhibition range, which eventually can be directly applicable to systems in which preventing certain single transitions is required.

In summary, we have investigated the optical and photoluminescent properties of the synthetic opal/CdS system. The growth of $\mathrm{CdS}$ through the CBD method has been shown to be an efficient technique to grow, in a controlled and uniform way, a semiconductor inside an opaline structure. Transmission measurements constitute a useful and nondestructive tool to control and quantify the growth ratio. Finally, such clear effects on the line shape of CdS photoluminescence, which can be easily controlled and manipulated by means of the sphere diameter, have been proven for this type of material. The inhibition observed could lead to a control of spontaneous emission of any active material, provided it could be grown inside the opaline host matrix.

This work was partially financed by Spanish CICyT Project No. MAT97-0698-C04, the EU Esprit project PHOBOS, and the Fundación Ramón Areces.

${ }^{1}$ E. Yablonovitch, Phys. Rev. Lett. 58, 2059 (1987).

${ }^{2}$ H. Míguez, C. López, F. Meseguer, A. Blanco, L. Vázquez, R. Mayoral, M. Ocaña, V. Fornés, and A. Mifsud, Appl. Phys. Lett. 71, 1148 (1997).

${ }^{3}$ H. Míguez, F. Meseguer, C. López, A. Mifsud, J. S. Moya, and L. Vázquez, Langmuir 13, 6009 (1997).

${ }^{4}$ H. S. Sözüer, J. W. Haus, and R. Inguva, Phys. Rev. B 45, 13962 (1992).

${ }^{5}$ H. Míguez, F. Meseguer, C. López, A. Blanco, J. S. Moya, J. Requena, A. Mifsud, and V. Fornés, Adv. Mater. 10, 480 (1998).

${ }^{6}$ H. Yates, W. R. Flavell, M. E. Pemble, M. P. Johnson, S. G. Romanov, and C. M. Sotomayor Torres, J. Cryst. Growth 170, 611 (1997).

${ }^{7}$ H. Yates, M. E. Pemble, H. Míguez, A. Blanco, C. López, F. Meseguer, and L. Vázquez, J. Cryst. Growth (to be published).

${ }^{8}$ V. N. Bogomolov, A. V. Prokofiev, S. M. Samoilovich, E. P. Petrov, A. M. Kapitonov and S. V. Gaponenko, J. Lumin. 71-74, 391 (1997).

${ }^{9}$ C. López, A. Blanco, H. Míguez, and F. Meseguer, Opt. Mater. (to be published).

${ }^{10}$ K. Yoshino, K. Tada, M. Ozaki, A. A. Zakhidov, and R. H. Baughman, Jpn. J. Appl. Phys., Part 2 36, L714 (1997).

${ }^{11}$ Y. A. Vlasov, V. N. Astratov, O. Z. Karimov, A. A. Kaplyanskii, V. N. Bogomolov, and A. V. Prokofiev, Phys. Rev. B 55, 13357 (1997).

${ }^{12}$ S. G. Romanov, A. V. Fokin, V. V. Tretijakov, V. Y. Butko, V. I. Alperovich, N. P. Johnson, and C. M. Sotomayor Torres, J. Cryst. Growth 159, 857 (1996).

${ }^{13}$ Y. A. Vlasov, K. Luterova, Y. Pelant, B. Hönerlage, and V. N. Astratov, Appl. Phys. Lett. 71, 1616 (1997).

${ }^{14}$ R. Mayoral, J. Requena, J. S. Moya, C. López, A. Cintas, H. Míguez, F. Meseguer, L. Vázquez, M. Holgado, and A. Blanco, Adv. Mater. 9, 257 (1997).

${ }^{15}$ C. López, H. Míguez, L. Vázquez, F. Meseguer, R. Mayoral, and M. Ocaña, Superlattices Microstruct. 22, 399 (1997).

${ }^{16}$ R. Mayoral, Ph.D. disertation, Universidad Autónoma de Madrid, October, 1997.

${ }^{17} \lambda=2 \times 0.816 D\left[\sqrt{\epsilon}_{(\text {silica })} 0.74+\sqrt{\epsilon}_{(\mathrm{CdS})} F+\sqrt{\epsilon}_{(\text {air })}(0.26-F)\right.$, where $F$ is the CdS filling inside the opal and $D$ the sphere diameter.

${ }^{18}$ O. Vigil, I. Reich, M. García-Rocha, and O. Zelaya-Ángel, J. Vac. Sci. Technol. A 15, 2282 (1997). 